\title{
Path Analysis on Big Data in Promoting Intelligent Tourism Implementation
}

\author{
Liu Guanglu ${ }^{1}$, Song Xiangye ${ }^{1}$,Liu hong ${ }^{1}$,Liu hongzhi²
}

1. Instructor of University of Science and Technology

Anshan Liaoning

2. Zhejiang University

Hangzhou Zhejiang

Iglgem@163.com; 15998067955@163.com; liaoningkejidaxue@126.com; mylhzem@163.com

Key words: big data; intelligent tourism; tourism planning; tourism informatization

\begin{abstract}
Intelligent tourism is the upper application to facing the visitors and severing them in the tourism informationization implementation process. Intelligent tourism development cannot leave the support of big data, which need to rely on large data to provide sufficient advantageous resources for "intelligent" development. However, the industry currently still has considerable obstacles for the application of large data, some are from the data collection, the others are from the data analysis and mining. This article states the usage of big data to intelligent tourism online reputation mechanism, data sharing mechanism, effective data using methods, and then provides useful methods for making the an accurate reflection of segments in intelligent tourism planning, timely finding products visitors concern for, and making tourism precision marketing.
\end{abstract}

\section{Introduction}

Tourism industry is an information intensive industry, which naturally contains a lot of big data. At the same time, it is a comprehensive industry, which consists of transportation, catering, service, and other industries. Under the trend of increasingly demand diversity, tourism is now coming into the rapid transition period from traditional industry to modern service industry. It now realizes the industry upgrade from the traditional to the modern service industry, based on a new generation of information technology and the original technology, ${ }^{[1]}$ which combines the big data platform of tourism information and resources, and it is expected to accelerate the tourism industry intelligent process. The traditional pattern of tourism management and service need innovation, so that the big data undoubtedly becomes the key force in the transformation of tourism to promote innovation. How to dig big data and use it becomes the development bottleneck and the realistic problem in tourism industry.

\section{Concepts of "Big Data" and "Intelligent Tourism" and Their Interactive Relationships}

Concept of "Big Data" and Its Characteristics

Nowadays, there are several concepts of big data as the followings: John Rauser, the Amazon big data scientist thinks that big data is "the huge of data that over a computer processing capacity." Dan Bin, the Chinese chief product consultant of Informatica, believes that " big data = mass data +complex types of data" ${ }^{[2]}$. Wikipedia defines big data as a large and complex data set that is difficult to deal with the existing database management tools. The core of big data is to predict results; and "Volume, Variety, Velocity and Value" are its significant characteristics ${ }^{[3]}$. In other words, it is the evidence of the four characteristics. The Intelligent tourism data has the four $\mathrm{V}$ characteristics, which can be applied to the analysis of large data and statistics.

Understanding Concept of "Intelligent Tourism" and Its System 
1) 1. "Smart Tourism" under "Tourism Informatization"

Along with the development of smart tourism practice, academia began to pay attention to smart tourism research, mainly concentrated in construction and application of the concept and the system of intelligent tourism ${ }^{[1,4-7]}$. Making understanding of smart tourism can be placed under the background of tourism informatization; information service is one of the core contents of smart tourism ${ }^{[1]}$. Intelligent tourism, in brief, uses new technology of cloud computing and Internet of Things, through the Internet or mobile Internet, with the help of the portable terminal device, to actively perceive tourism resources, tourism activities, tourists, and other information, which makes people know the information in time, arrange and change their travel plans, so that to realize the effect of intelligent perception of various tourism information and convenient use of it.

2) "Intelligent Tourism" Is Different from " Tourism Informatization"

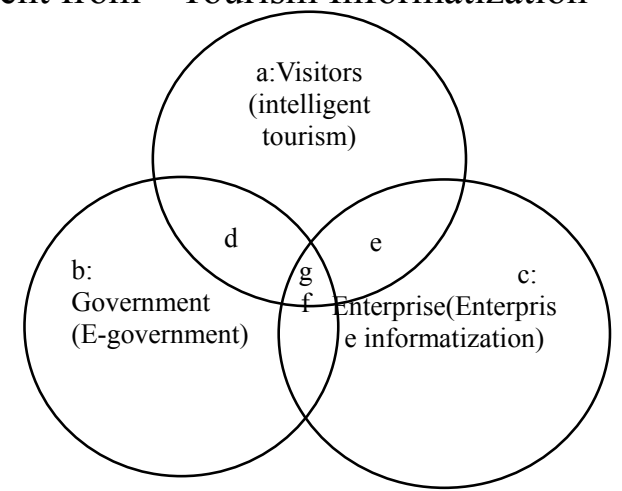

Figure 1 Relationships between Tourism Informatization and Intelligent Tourism

a: tour guide, information guide, purchasing guide, and navigation

b: OA; statistical information platform; E-Government website

c: ERP、CRM、supply chain management

$\mathrm{d}$ : Public information service for visitors provided by government( climate; visitor flow volume; traffic information)

e: Service for visitors provided by enterprises (on-line tourism; tourism e-commerce; on-line consultation service)

f: Enterprise industry management by government( Monitoring service quality)

g: Data Center Cloud; Internet of Things; Net Platform; communication facilities

As shown in figure 1, intelligent tourism is not the same as the traditional tourism informatization, the latter has larger area then intelligent tourism. Tourism informatization consists of three subjects of visitors, enterprises, and the government. The government sets up egovernment affairs; the enterprises implement information management; however, only tourism informatization, facing and serving visitors, is called intelligent tourism. In the process of this service implementation, "intelligent" is rooted in the whole process of service, including the pre purchase, the travel, and post purchase of tourism: pre purchase solves the problems of the motivation, the travel solve the problem of action, and post purchase solves problem of sharing. This indicates that the "intelligent tourism" is not only confined to the intelligent tourism marketing, it is just one function of intelligent. It cannot replace other marketing methods, even is not equal to network marketing.

3) System of Intelligent Tourism

From the perspective of users, intelligent tourism mainly includes four functions of navigation, tour guide, information guide, and purchasing guide. ${ }^{[6]}$. It starts with location service (navigation); secondly it makes a preliminary understanding of the surrounding information (tour guide); then it makes in-depth understanding of the surrounding information (information guide); finally through a comprehensive and in-depth understanding and online analysis, it realizes the direct online booking rooms/ticket (purchasing guide). The "Four guides" realizes the "one-stop," "continuous" model to provide information services for visitors. Therefore we can see the structure of the "intelligent tourism" mainly includes three parts ${ }^{[8]}$, which are: "One center, Two terminals, and Three nets", which is shown in figure 2 : 
Interactive Relationships between "Big Data" and "Intelligent Tourism"

In the nowadays of rapid development of informatization, the development of intelligent tourism cannot leave the big data, thousands of visitors" individual data integrate the "big data" [1]. Both in administration and service organizations, they rely on big data to provide sufficient advantageous resources. With the aid of the relevant relationships in "big data," intelligent tourism can be "intelligent" development. Intelligent tourism emphasizes the intelligence, which is not only provide tourism information of simple one-way or one-point, but the new integration and design of getting and purchasing the all information in the whole process of pre purchase, the travel, and post purchase period, which could make visitors get convenience and unique experience from the process by the technology innovation.

Meanwhile, the intelligent tourism city development cannot leave the big data support, relying on big data, we can exactly know the trend, flow, and satisfaction of visitors. For example, based on intelligent tourism platform, tourism administrative management departments can provide better traffic guidance and control, offer visitors more choices of alternative tourism plan and emergency strategy, and can accurately reflect where is the visitor market, which products the visitors focus on, which can play a key role in decision marketing.

\section{Construction Situation of Intelligent Tourism}

4) "Internet + " will make platform base for big data in intelligent tourism implement

As shown in figure 3 and 4 , according to the $36^{\text {th }}$ time survey report of CNNIC, until June 2015, Chinese Internet penetration rate is $48.8 \%$, there are 668 million Internet users. Among them, 594 million mobile Internet users, the users increased from 85.8\% in December 2014 to $88.9 \%$.

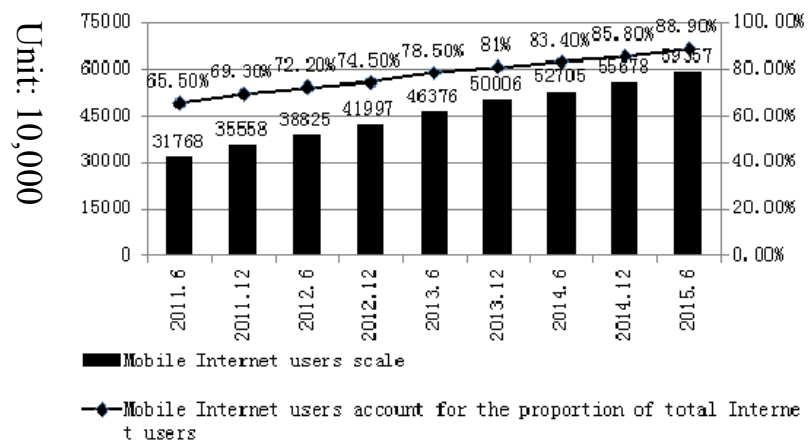

Figure 3 The Number of Chinese Netizens and Penetration Rate of Internet

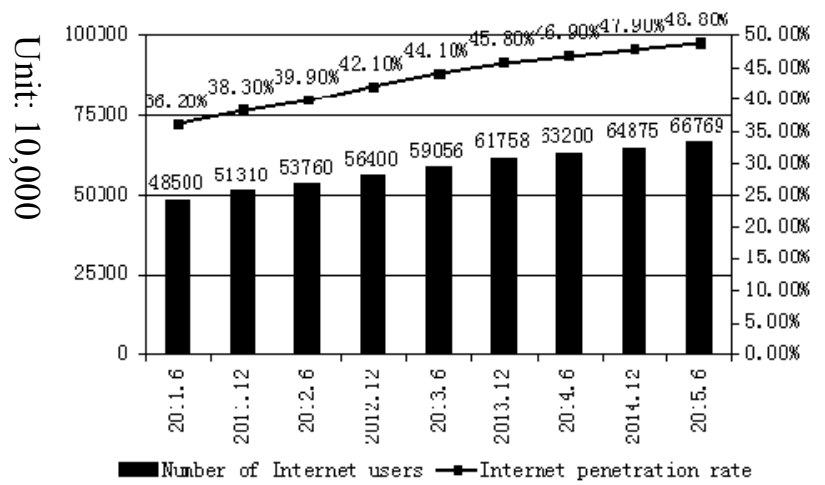

Figure 4 The Number of Chinese Mobile Phone Netizens and Its Ratio

With the action plan of "Internet +", the Internet accelerates the transformation and upgrading of the traditional travel service industry, makes the new economical development form based on the Internet as basic facilities and tools, which provides a platform for intelligent tourism planning. Among the main channels for visitors to get tourism information, a lot of ways are through the intelligent terminal equipment, such as the computer, the mobile phone, and the tablet PC, the involved information range and types permeate various industries via Internet and mobile Internet, mainly focus on the tourism demand change from the former six elements (traveling, touring, staying, tasting, purchasing and entertaining) into the new " $6+\mathrm{N}$ " elements (traveling, touring, staying, tasting, complaining, sharing, purchasing, entertaining, ...) . 
5) Development of Intelligent Tourism Is Still on the Concept Stage

Although the application prospect of big data in tourism industry is very broad, but there are still considerable barriers for big data applications, which not only from the data collection, but also from the data analysis and excavating. The most different between intelligent tourism and traditional tourism is to break the barriers of the space and the place. Under the ideal situation of intelligent tourism, the users can search, entertainment, and amuse at any time, anywhere, at will; all their behaviors can be coordinated among the clouds. However, from the feedback of segmentation, only the map navigation, logistics, travel, and other infrastructures are relatively perfect, the other modules are not integration, and cannot develop coordinately. Among them, the basic infrastructures, such as the scenic spot electronic ticket, the hotel online booking, the transportation information publish, has not yet to form a chemical reaction. Especially the data level is still not fully open, it cannot achieve mutual coordination, and sharing; various segmentations still separately focus on their own ways.

6) The Blind Decision Makes Poor Effect of Marketing and publicity

Although there are various intelligent visitor attractions in current intelligent tourism, they are fragmented. On one hand, due to the lack understanding of the Internet or mobile Internet by the decision leaders, they did not know the concept of big data deeply, so that they made many blind decisions. There was no good effect with the investment of technology, which lost many former users. We put a large amount of manpower and material resources and financial resources in it, but get no effect of spreading and marketing. On the other hand, the developers didn't consider in the perspective of the real visitors to design and use the data, just though advertisement to get profit, which couldn't satisfy the customers' demands, and then put them into mistake. Actually, visitors are the core value of intelligent tourism.

7) No Convenient, Transparent, and Visual Information Platform

"Big data" puts forward higher requirements on experience of intelligent tourism, particularly in establishing data information platform and business operation models. Most of the existing intelligent tourism information at home and abroad realizes the given process to finish experience sharing: firstly, through search engines to find the intelligent tourism information service platform; Secondly, to provide special third - party APP to make programs classification; Thirdly, to use OTA technology to download the relevant interesting tourism information; Finally, to complete the deal on the $\mathrm{O} 2 \mathrm{O}$ platform. In order to realize the well done of the four links, we need to establish a full, convenient, transparent, and visual information platform, which could play a key role in domestic intelligent tourism development.

\section{Assistant Path for "Big Data" to Intelligent Tourism}

When consumers use "comparison shopping" method to reduce the decision-making risk, they need for more information ${ }^{[9]}$. A huge amount of data in big data era satisfied such demand, however, more data didn't mean the better decision for visitors, it only found a now way to let the abundance of data from the "much" to the level of "little"; the big data could really impact and help consumers ${ }^{[9]}$.

8) Establishing Tourism Online Reputation Mechanism

Vast amounts of comment data could often make tour operators have no idea. The rapid spread of network information can intensify the influence of the bad comments; if the tourism enterprise makes a lag of solving the problem, it will affect the corporate image. Differently from the traditional telephone complains to reflect their dissatisfaction, online comments have the characteristics of timeliness and diffusivity. How to use these comments to expand the positive effects and reduce the negative effects is the new task for tourism enterprises. In addition, the more and more new challenges of big data become in front of the tour operators.

The establishment of the tourism online reputation mechanism is not simply in network space to show as far as possible much good comments, it needs to find a balance in the multiple sets of relationships, that is the core of tourism online reputation mechanism establishment. These balance include: looking for the balance between huge amount of data production and use reduction, the 
balance between the real-time dynamic monitoring and timely updating, the balance between the information rich supply and effective evidence, the balance between the data inventory and matching push data ${ }^{[9]}$. For example, with the development of the tourism industry, the scenic area can make use of big data to improve service quality. Some provinces (cities) government open various media accounts, such as a Microblog or We-chat, they try to establish a closer relationship with visitors. Secondly, some scenic spots have a higher request for their images, appetite for destination marketing; thirdly, the information association offers visitors the entrance for better understanding of the attractions. For example, Weihai City has set up such network at present, which can make visitors quickly know various types of information.

9) Establishment of Data Sharing Mechanism

In the range of the world, visitors emphasize on comment information on social platform and web site, which almost become the key factors for their travel booking and relevant decisions. Data sharing mechanism makes other people's experience become the "precursor" of their own experience, which changes the "posteriority" characteristic of the tourism consumption and the decision-making model, and raises the possibility of right tourism consumption decision and the healthy development of the tourism industry.

At the same time, big data technology can be applied in demand management and forecasting, product, and revenue management, service and performance management, information sharing and collaboration of tourism enterprises. Tourism enterprises should strengthen enterprise internal digital degree from the internal management system, and optimize the internal management process. In the aspect of customer management, they should strengthen the collection of customer information, pay attention to the accumulation of customers' data. Through the analysis of large amounts of data, they guide and manage the operations. For example, hotels can suggest attractive tourism products and service more accurately according to the characteristics and preferences; tourist scenic spots can make better traffic guidance and control; travel agencies can more easily integrate information resources and develop a more targeted and personalized tourism products.

At the same time, tourism enterprises can also establish a large regional operation monitoring management services platform, which integrates more than 10 relevant tourism industries' data of the tourism industry, the public security system, the traffic system, the statistics system, the environmental protection system, the communication system. Just as the network director of "Qunar.com," Qiu Hui said that only more opening data, the data era could truly come.

10) Effective Data Application Method in Big Data Era

"Big data era lacks of methods, not the data." In an age of abundant data, everyone would have a huge data, but how do collect, develop, and use the data is the root of the problem. The former tourism information collection method depended on the data from the scenic spots and local travel bureau, which was macro, no unified statistical standards, and lack of accuracy. The information about consumption spending, consumption habits and scenic spots where visitors focus on cannot be fully analyzed. No longer using the methods of original questionnaire, and sampling, we could use a whole sample data collection and analysis, and then we could find the essence. For example, the satisfaction measurement in traditional questionnaire would inevitably include some subjective factors and make evaluation is not objective. If we use public opinion analysis to analyze the voice and the semantic of comments and complains, to extract the keywords and set up models and rules, which could automatic identify the visitors' needs or questions, make public opinion direction in advance, consequently improve the satisfaction of visitors.

Meanwhile, the era of big data promotes intelligent tourism to realize "O2O" marketing model, namely online marketing, which through purchasing to develop below the line operation and consumption. For example, through methods such as discount, provide information and services reserved to send consumption of the below-the-line stores to the Internet users, which could bring them to become their own below-the-line customers. At the same time, through the cooperation with the national large-scale Internet search engine companies, and OTA enterprises, we could develop tourism search times data system, tourist marketing data system, and tourism new media data system to realize precision marketing. To visitors' experience, Baidu tourism business department found that when visitors book hotels, $29 \%$ visitors are focus on guestroom's type 
pictures. The department uses intelligent tools to make $360^{\circ}$ view of panorama, which can let visitors to have a better understanding of the hotel room.

\section{Conclusion}

Intelligent tourism development cannot leave the big data, which relies on sufficient advantageous resources; with that tourism can be "intelligent" development. ${ }^{[10]}$ All levels of tourism departments should emphasize on the intelligent tourism concept make efforts to build tourism information platform construction, need to formulate relevant standards. The data information both from on-line and below the line should be searched and analyzed with the standards, to avoid the abuse of the big data. The tourism enterprises should clear the development direction of tourism industry, not the standardization, but the characteristic; they should pay attention to the big data construction on management, develop large data as the key point of the future work direction. From data store to product search, then to customer service, which creates a coordinated process intelligent tourism service system; it could make customers get more satisfied service in tourism.

Source:(as20153006)2015 Anshan Social Science Research Project Research Results

\section{Reference}

[1] Li Yunpeng, Hu zhongzhou, Huang Chao, Duan Liqiong. The Concept of Smart Tourism under the Context of Tourism Information Service [J]. Tourism Tribune, 2014, 05:106-115.

[2] Dan Bin, Big Data= Huge Data+ Complex Types Data [EB/OL].2012.7.

[3] Philip Russom. Big data analytics. TEWI Best Practices Report 2011.

[4] Chen Tao, Xu Xiaolin, Wu Yulong, Intelligent Tourism: Modern Tourism Industry Development Ways under the Background of Internet of Things [M]. Beijing: Publishing House of Electronics Industry, 2012:15.

[5] Zhang Lingyun, Li Nao, Liu Min, On the Basic Concept of Smarter Tourism and Its Theoretical System [J]. Tourism Tribune, 2012, 27 ( 5):66-73.

[6] Huang Yangshan, Liu Wenna, Intelligent Tourism-Applications for Visitors [M].Nan Jing: Southeast University Press, 2013: 7-8,98.

[7] Li Yunpeng, Chao Xi, Shen Yuhua, Intelligent Tourism: From Tourism informatization to Tourism Intelligence [M]. Beijing: China Travel \& Tourism Press, 2013: 67.

[8] Liu Junlin, Fan Yunfeng, The Form, Value and Development Trend of Intelligent Tourism [J].Chongqing Social Science, 2011 (10): 121-124.

[9] Qi Zheng, online public opinion needs Tourism Online Reputation Evaluation Mechanism [N] .China Youth Daily, 2014-11-21.

[10] Luo Chengkui, Big Data Application in Intelligent Tourism [J].Tourism Overview (The 2nd Issue of the Month) 2013, (8):59-60. 


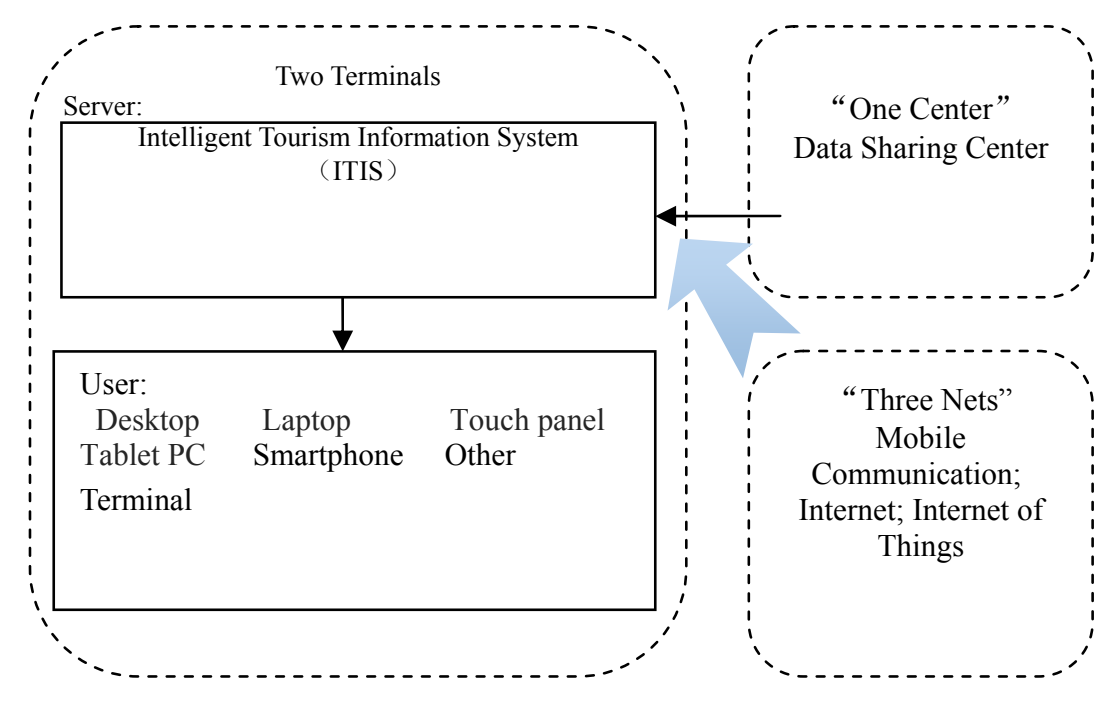

Figure 2 Tourist information technology relationship with wisdom tourism 